Gut, 1988, 29, 336-341

\title{
Secretory effect of azodisalicylate (azodisal sodium) on the short circuited mucosa of the rat ileum in vitro
}

\author{
K J GOERG, R WANITSCHKE, PH DIEHL, AND \\ K H MEYER ZUM BÜSCHENFELDE \\ From the First Medical Clinic of the Johannes Gutenberg University, D-6500 Mainz, FRG
}

SUMmary Azodisalicylate (ADS) is one of the newly developed substitutes of sulphasalazine consisting of two molecules of 5-aminosalicylic acid. Azodisalicylate caused diarrhoea in some patients, apparently caused by an antiabsorptive secretagogue action of this compound. The mechanism of this was studied in the short circuited isolated mucosa of the rat ileum. Mucosal addition of ADS increased the potential difference (PD) and short circuit current ( $\left.I_{s c}\right)$ at a concentration of $1.3 \cdot 10^{-4} \mathrm{~mol} / \mathrm{l}(4 \mathrm{mg} / \mathrm{dl})$ with maximal effects at $1.3 \cdot 10^{-3} \mathrm{~mol} / \mathrm{l}(40 \mathrm{mg} / \mathrm{dl})$. Epithelial resistance was only slightly decreased at the higher concentrations of 40 and $100 \mathrm{mg} / \mathrm{dl}$. Serosal ADS had no effect on electrical parameters. The increase of $I_{\text {sc }}$ was associated with a change of net chloride absorption into net secretion. Net sodium absorption was only slightly and not significantly decreased. The changes were reversible after rinsing away the ADS. Treatment of the mucosa with furosemide inhibited the ADS induced increase of $I_{\text {sc }}$, suggesting transcellular pathway for the ADS stimulated secretion. Biosynthesis of prostaglandins is not involved in the mechanism of this secretion, as treatment with indomethacin did not alter the effect of ADS on $\mathbf{I}_{\text {sc }}$. Results suggest that ADS can be considered as a secretagogue, which stimulates intestinal secretion via a transcellular pathway. Because of the bacterial cleavage of the double molecule into two molecules of the nonsecretagogue 5-aminosalicylic acid in the colon, however, diarrhoea may develop only in patients with a decreased absorptive capacity of the colon, or insufficient cleavage of ADS.

Sulphasalazine (SASP) consists of a double molecule, in which 5-amino-salicylic acid (5-ASA) and sulphapyridine are connected by an azo bond. This double molecule is split in the colon by bacterial azoreductases into sulphapyridine and 5-aminosalicylic acid, the therapeutically active moiety. ${ }^{1-5}$ Because a varied spectrum of adverse effects is known in the therapy of ulcerative colitis with SASP mostly related to the sulphapyridine part of SASP, ${ }^{67}$ some possible sulpha free substitutes were developed in recent years - for example, azodisalicylate $=$ azodisal-sodium $=$ olsalazine sodium (ADS), which was considered as an optimal substitute of SASP. ${ }^{8}$ It consists of two molecules of 5-ASA connected by an azo bridge, which is easily split in the colon and delivers twice the amount of 5-ASA into the colon on

Address for correspondence: Dr K J Goerg, First Medical Clinic of the Johannes Gutenberg University, D-6500 Mainz, FRG.

Received for publication 24 August 1987 a molar basis. ${ }^{9}$ This compound caused no adverse effects (especially no diarrhoea) when tested by peroral application in healthy volunteers. ${ }^{9}{ }^{10}$ The first clinical trial with ADS, however, has shown that exacerbation of diarrhoea or loose stools occurred in $15.5 \%$ of 160 patients. "This was apparently related to a secretory action of ADS which we recently demonstrated in the rat ileum and colon in vivo. ${ }^{12}$

The aim of this paper is to study the mechanisms of the secretory effects of ADS. Therefore, the action of ADS on electrical parameters and ion fluxes was tested on the isolated mucosa of the rat ileum under short circuited conditions.

Methods

PREPARATION

Under ether anaesthesia, the distal $5 \mathrm{~cm}$ of the ileum was removed and placed in an ice cold bath. After 
rinsing free of luminal contents the ileum was placed on a plastic rod with a diameter of $3 \mathrm{~mm}$. A longitudinal incision was made with a blunt scalpel and the serosa, muscularis propria, and most of the submucosa were stripped away. The preparation on the rod was then cut lengthwise along the mesenteric border and mounted as a flat sheet in a modified Ussing chamber. Chambers were water jacketed and thermostatically maintained at $37^{\circ} \mathrm{C}$. The mounted mucosa with an exposed surface area of $1 \mathrm{~cm}^{2}$ was bathed on both sides with $3.5 \mathrm{ml}$ of an electrolyte buffer solution and continuously gased with carbogen $\left(95 \% \mathrm{O}_{2}\right.$ and $\left.5 \% \mathrm{CO}_{2}\right)$ through a piece of sintered glass.

\section{ELECTRICAL MEASUREMENTS}

The potential difference (PD) between the mucosal and serosal side was measured with calomel electrodes in saturated $\mathrm{KCl}$ over agar bridges $(4 \mathrm{~g} \%)$ positioned near each surface of the tissue. The PD was continuously short circuited via agar bridges at the opposite end of the chambers over $\mathrm{Ag} / \mathrm{AgCl}$ electrodes with the aid of an automatic voltage clamp device (Dr G Haas, Elektronische Geräte, Randweg 45, D-6100 Darmstadt, West Germany). Potential difference recording was possible under open circuit conditions by switching off the short circuit current for five seconds. Before mounting the tissues, the Ussing chamber was corrected for offset potential and solution resistance. An additional compensation of the resistance in series originating from the connective tissue in the mucosal membrane was possible by registration of the voltage deflection caused by square wave current impulses. This additional compensation is most important in epithelia with low resistance. In the ileum, total tissue resistance was reduced by $10 \Omega \mathrm{cm}^{2}$ by this compensation. Twenty to 30 minutes after mounting the tissue into the Ussing chamber, when electrical parameters were stabilised, the following experiments were performed.

(1) To study the concentration dependence of the ADS effects on electrical parameters, ADS was added either to the mucosal or serosal side of the tissue in concentrations of $0 \cdot 2-200 \mathrm{mg} / \mathrm{dl}$ and $6.6 \cdot 10^{-6}-6.6 \cdot 10^{-3} \mathrm{~mol} / \mathrm{l}$ respectively. Each addition was followed by several rinses of both sides after obtaining maximal changes of electrical parameters. No desensitisation could be observed with this procedure. Effects of single additions of ADS were not different from effects obtained after repeated additions of ADS.

(2) Unidirectional fluxes of sodium and chloride were determined by adding both isotopes to one side of the tissue. After 10-15 minute samples of $200 \mu \mathrm{l}$ were taken from both sides and replaced with an equal volume of unlabelled solution. Thereafter,
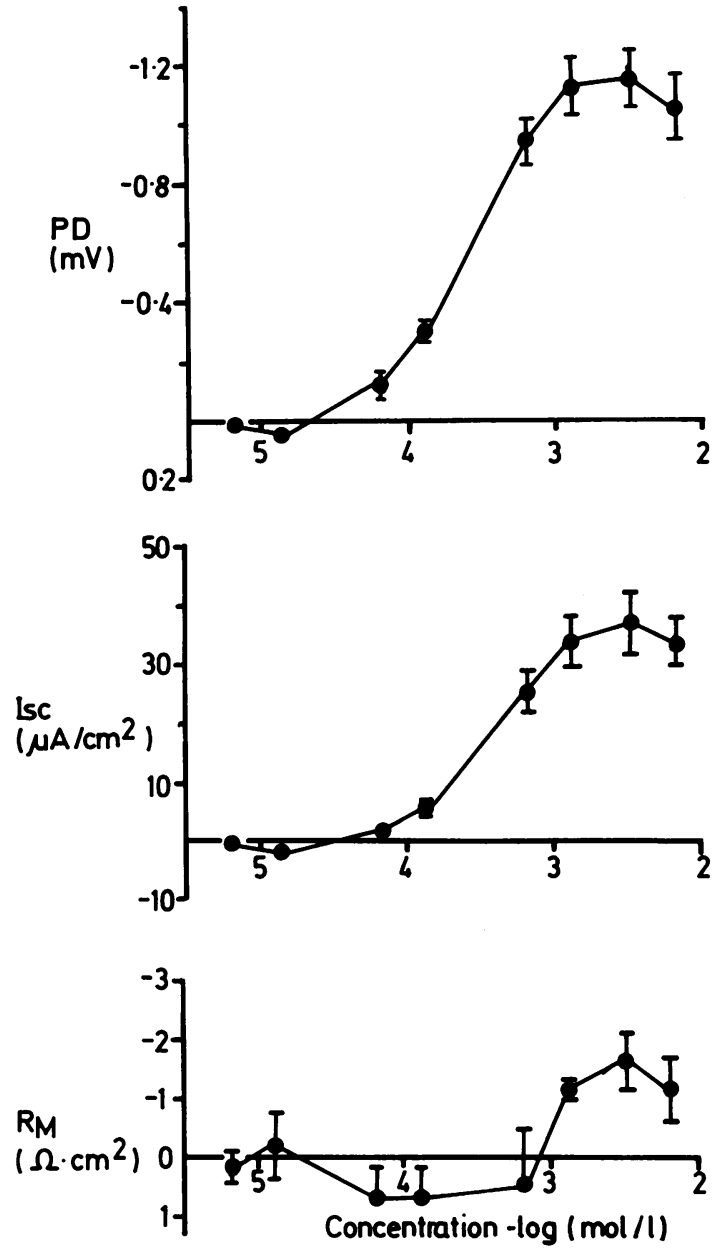

Fig. 1 Concentration dependence of the changes in potential difference ( $P D$, upper panel), short circuit current $\left(I_{\mathrm{sc}}\right.$, middle panel) and epithelial resistance $\left(R_{\mathrm{M}}\right.$, lower panel) under the influence of $A D S$ given to the mucosal side of the ileal mucosa. Every concentration was tested in each sheet with multiple rinses of both sides of the Ussing chamber after each concentration. The negative $P D$-values are related to the negative charge on the mucosal side which is short circuited to zero by an oppositely directed current. Mean values $(S E) n=6$.

samples were taken after a 30 minute interval. The serosal sample was then replaced by the electrolyte buffer solution. The mucosal sample was replaced by an equal volume of electrolyte buffer with ADS, resulting in a mucosal ADS concentration of $6.6 \cdot 10^{-4}$ $\mathrm{mol} / \mathrm{l}(20 \mathrm{mg} / \mathrm{dl})$.

After another 30 minutes, samples were taken again from both sides. Both chamber halves were rinsed several times after this ADS-flux period with a total volume of $20 \mathrm{ml}$ of the buffer solution on each 
side during a rinse period of 30 minutes. After this rinse period both sides of the Ussing chamber were filled with a preweighted volume of $3.5 \mathrm{ml}$ of the electrolyte buffer. One side of the Ussing chamber was labelled with ${ }^{36} \mathrm{Cl}^{-}$and ${ }^{22} \mathrm{Na}^{+}$. After 5 minutes, when electrical parameters were stabilised after the exchange of the chamber volume and 30 minutes later samples were taken again from both sides.

(3) Effect of furosemide and indomethacin on the effect of ADS on electrical parameters.

The effect of furosemide was tested by serosal addition of this substance after mounting the tissue resulting in a serosal concentration of $5 \cdot 10^{-4} \mathrm{~mol} / \mathrm{l}$. After 30 minutes ADS was added to the mucosal side in a concentration of $6.6 \cdot 10^{-4} \mathrm{~mol} / \mathrm{l}$. Thirty minutes later both sides were rinsed with electrolyte buffer containing furosemide over a $\mathbf{3 0}$ minute rinse period and the tissue was studied for another 30 minute interval.

To study whether the endogenous prostaglandin biosynthesis is involved in the secretory action of ADS, indomethacin was added to the serosal and mucosal side of the tissue resulting in a concentration of $5 \cdot 10^{-6} \mathrm{~mol} / \mathrm{l}$. When steady state conditions were attained, electrical parameters were recorded for 30 minutes. Azodisalicylate was then added to the mucosal side of the Ussing chamber in a concentration of $6.6 \cdot 10^{-4} \mathrm{~mol} / \mathrm{l}$ and electrical parameters were followed up for another 30 minute period. Thereafter, both chamber sides were rinsed several times with the buffer solution over a rinse period of 30 minutes and electrical parameters were recorded for another 30 minutes.

\section{SOLUTIONS}

The bathing solution contained (mmol/l): $\mathrm{NaCl} 107$, $\mathrm{KCl} 4 \cdot 5, \mathrm{NaHCO}_{3} 25, \mathrm{Na}_{2} \mathrm{HPO}_{4} 1 \cdot 8, \mathrm{NaH}_{2} \mathrm{PO}_{4} 0 \cdot 2$,

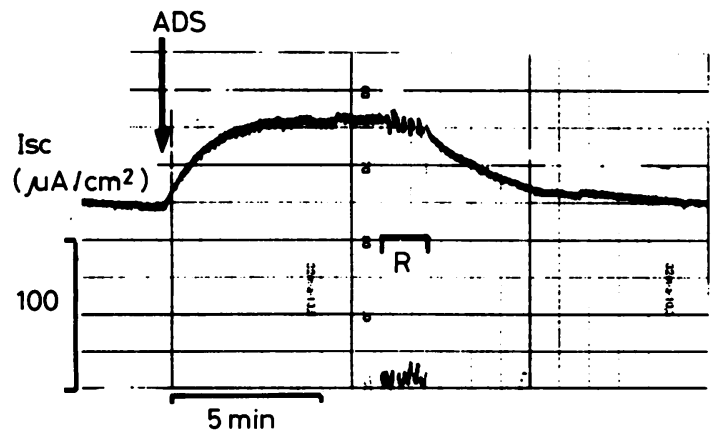

Fig. 2 Typical time course of the effect of mucosal addition of $A D S$ in a concentration of $6.6 \cdot 10^{-4}$ molll on the short circuit current $\left(I_{\mathrm{sc}}\right)$. The increase of $I_{\mathrm{sc}}$ to a new plateau was reversible within 5 minutes after several rinses $(R)$ of both sides of the Ussing chamber with control solution.
$\mathrm{CaCl}_{2} 1 \cdot 25, \mathrm{MgSO}_{4} 1 \cdot 0$, and glucose 12 . The solution had a pH of 7.4 when gased with carbogen $\left(95 \% \mathrm{O}_{2}\right.$ and $5 \% \mathrm{CO}_{2}$ ).

MEASUREMENT AND CALCULATIONS

Isotope activities were determined by sequential counting in a Picker spectroscaler and a Packard TriCarb liquid scintillation spectrometer. Unidirectional $\mathrm{Na}^{+}$and $\mathrm{Cl}^{-}$fluxes (Jms, Jsm) were calculated using standard equations. The residual ion flux $\left(\mathrm{I}_{\mathrm{R}}\right)$ was calculated from the differences in the $I_{s c}$ and net sodium ( $\mathrm{H}_{\text {net }}{ }^{+}$) and chloride ( $\mathrm{I}_{\text {net }}^{\mathrm{Cl}^{-}}$) fluxes: $\mathrm{I}_{\mathrm{R}}=\mathrm{I}_{\mathrm{sc}}-$ $\left(\mathrm{J}_{\text {net }}^{\mathrm{Na}^{+}}-\mathrm{J}_{\text {net }}^{\mathrm{C}}\right.$ ). Results are given as the mean (SE). Significance of differences was tested using a twotailed $t$ test. Paired or unpaired tests were used.

\section{Results}

CONCENTRATION DEPENDENCE

As is shown in Figure 1, ADS concentration dependently increased the PD and $I_{s c}$ when added to the mucosal side at a threshold concentration of $\left.1.3 \cdot 10^{-4} \mathrm{~mol} / \mathrm{l}(4 \mathrm{mg} / \mathrm{dl}), \mathrm{p}<0 \cdot 02\right)$. Maximal effects were obtained at a concentration of $1.3 \cdot 10^{-3} \mathrm{~mol} / \mathrm{l}(40$ $\mathrm{mg} / \mathrm{dl}), \mathrm{p}<0.001)$. There was only a small decrease of epithelial resistance at the higher concentrations of 40 and $100 \mathrm{mg} / \mathrm{dl}$ ( $\mathrm{p}<0.001$ and $\mathrm{p}<0.02 \mathrm{resp}$ ). Serosal application was without effect on electrical parameters. Effects after application of ADS to both sides of the tissue were not different from effects obtained after mucosal application of ADS. After addition of ADS the increase of $I_{s c}$ was prompt. A maximal increase of the $I_{s c}$ to a new plateau was obtained after three to five minutes (Fig. 2). Complete reversibility was obtained after several rinses of both sides of the Ussing chamber with central solution.

\section{INFLUENCE OF ADS ON ION TRANSFER}

During the 30 minute control interval, MS fluxes of sodium and chloride in the short circuited ileal mucosal significantly exceeded SM fluxes resulting in a net sodium and chloride absorption. Net chloride absorption was significantly lower $(\mathrm{p}<0.01)$ than net sodium absorption. The measured $\mathrm{I}_{\mathrm{sc}}$ did not differ significantly from the difference between net sodium and chloride absorption and $I_{R}$ did not differ from zero (Fig. 3).

After application of ADS to the mucosal side in a concentration of $6.6 \cdot 10^{-4} \mathrm{~mol} / \mathrm{l}$, the $\mathrm{PD}$ increased from $-4 \cdot 1(0 \cdot 28)$ to $-5 \cdot 1(0 \cdot 24) \mathrm{mV}$ (mucosal side negative, $\mathrm{p}<0 \cdot 0001$ ) values expressed as mean (SE), the $I_{s c}$ increased from 143.9 (7) to $188.4(8.7)$, $\mu \mathrm{A} / \mathrm{cm}^{2} \quad(\mathrm{p}<0.001)$. Epithelial resistance was decreased from $29.8(1.5)$ to $27.9(1.5), \Omega \mathrm{cm}^{2}$ (ns). The unidirectional flux Jsm of sodium was increased $(p<0.001)$ during this ADS interval, as was also the 


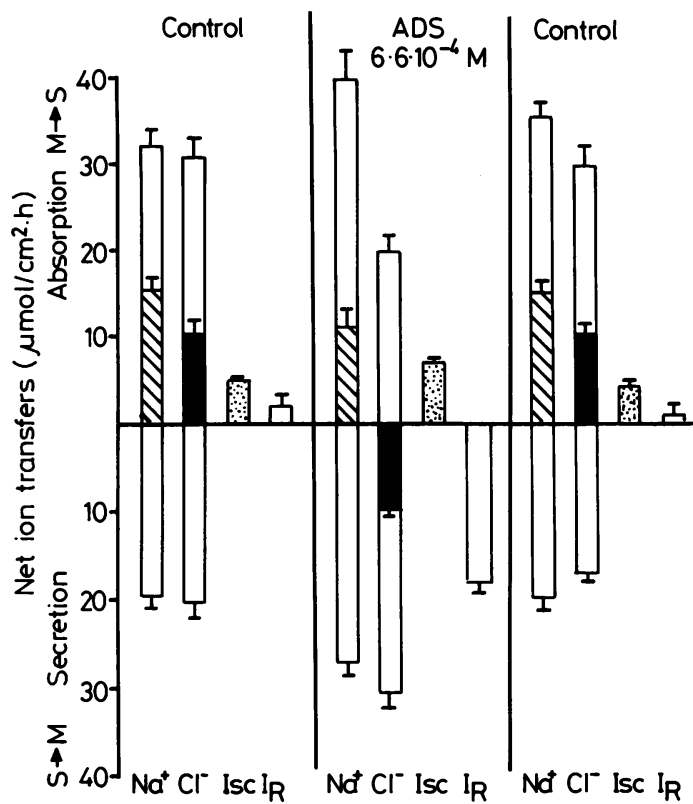

Fig. 3 Unidirectional and net ion fluxes under control conditions, after addition of $A D S$ to the mucosal side, and during another control period after a rinse period of 30 minutes. Open columns represent unidirectional fluxes, black columns represent net chloride fluxes, and striped columns represent net sodium fluxes.

Jms of sodium (ns), resulting in a net sodium absorption, not different from the preceding control interval. In contrast Jms of chloride was significantly decreased $(\mathrm{p}<0.001)$ and Jsm of chloride was significantly increased $(\mathrm{p}<0.001)$ causing a net secretion of chloride of $-6.5 \mu \mathrm{mol} / \mathrm{h} / \mathrm{cm}^{2} \quad(2 \cdot 4) \quad(\mathrm{p}<0.0001)$. These changes in chloride transfer were, however, only represented in part by the increase in $\mathrm{I}_{\mathrm{sc}}$ so that an additional movement of another charged molecule has to be taken into account, which is represented by a significant change of $I_{R}$ $(\mathrm{p}<0.00001)$.

When the Ussing chambers were rinsed on both sides with the control buffer solution $\mathrm{I}_{\mathrm{sc}}$ decreased to $128.5 \mu \mathrm{A} / \mathrm{cm}^{2}(7 \cdot 1)$ and epithelial resistance increased to $30.9 \Omega \mathrm{cm}^{2}(1 \cdot 8)$. Both these values were not significantly different from the previous control period. Unidirectional and net ion fluxes were also not significantly different from the flux rates measured during the control interval (Fig. 3).

\section{EFFECT OF PRETREATMENT WITH FUROSEMIDE OR INDOMETHACIN}

The time course of $I_{s c}$ under control conditions, after mucosal addition of ADS $\left(6.6 \cdot 10^{-4} \mathrm{~mol} / \mathrm{l}\right)$ and after washout of ADS by multiple rinses of both sides at
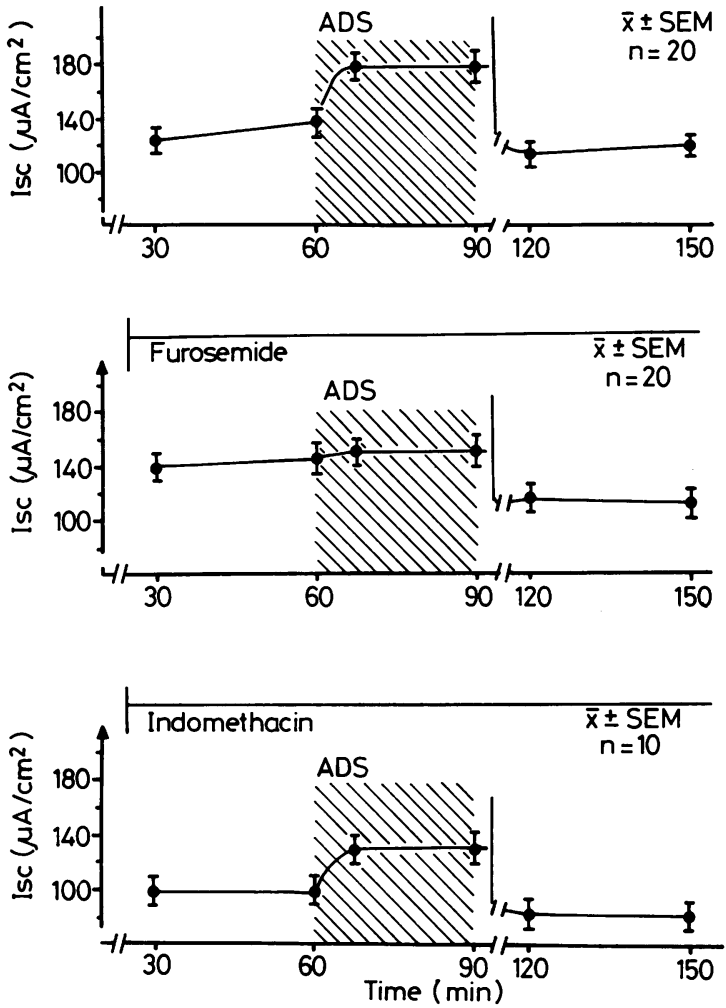

Fig. 4 Effect of ADS $\left(6.6 \cdot 10^{-4} \mathrm{~mol} / \mathrm{l}\right)$ on short circuit current $\left(I_{\mathrm{sc}}\right.$, upper panel), after pretreatment with furosemide in a concentration of $5 \cdot 10^{-4}$ mol/l on the serosal side (middle panel), and after pretreatment with indomethacin in a concentration of $5 \cdot 10^{-6}$ mol/l on both sides of the tissue. $V$ rertical lines after the $A D S$ period represent several rinses of both sides of the Ussing chamber with control solution.

the Ussing chamber is shown in Figure 4. During the control interval the $I_{s c}$ remained stable on the same level.

Addition of ADS increased $I_{s c}$ to a significantly higher level $(p<0.001)$, which proved to be reversible after washout of ADS (Fig. 4, upper panel).

Pretreatment of the ileal mucosa with furosemide applied to the serosal side in a concentration of $5 \cdot 10^{-4}$ $\mathrm{mol} / \mathrm{l}$ had no significant influence on $\mathrm{I}_{\mathrm{sc}}$ under control conditions. Addition of ADS to the mucosal, however, side was not followed by an increase of $\mathrm{I}_{\mathrm{sc}}$. When the ileal mucosa was treated with indomethacin in a concentration of $5 \cdot 10^{-6} \mathrm{~mol} / \mathrm{l}$ at both sides of the Ussing chamber, the $I_{s c}$ was slightly reduced under control conditions. The increase of $I_{s c}$ caused by ADS was not blocked by this concentration of indomethacin and also not by a concentration of $3 \cdot 10^{-5} \mathrm{~mol} / \mathrm{l}$ (Fig. 4 lower panel, Fig. 5) at which a complete inhibition of endogenous prostaglandin biosynthesis has been described. ${ }^{13}$ 


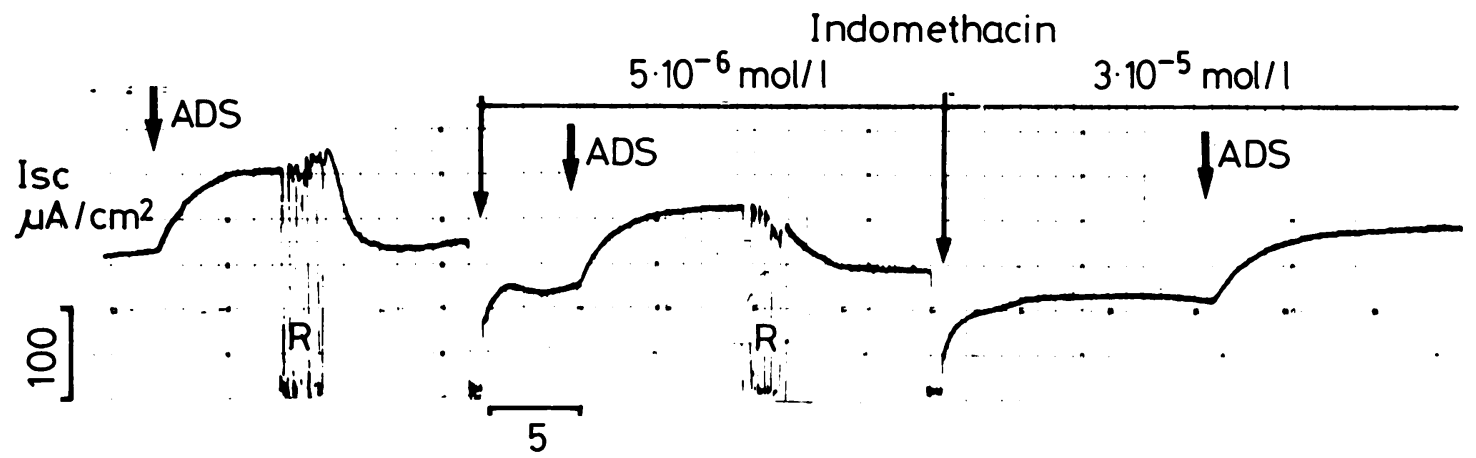

Fig. 5 Tracing of the effect of $A D S\left(6.6 \cdot 10^{-4}\right.$ molll, mucosal addition) without and after pretreatment with indomethacin on both sides of the tissue.

\section{Discussion}

Although peroral application of ADS caused no adverse effects, particularly no diarrhoea, when tested in healthy volunteers, ${ }^{910}$ the first clinical trial with ADS has shown that exacerbation of diarrhoea or loose stools occurred in $15.5 \%$ of 160 patients, apparently related to a secretory action of ADS. "In tied-off loops of the rat ileum and colon in vivo, we have recently shown that ADS decreased net absorption of water, sodium and chloride in a concentration dependent manner and stimulated net secretion in concentrations higher than $100 \mathrm{mg} / \mathrm{dl} .{ }^{12}$ Similar results were obtained in perfusion studies of the human jejunum and colon (Wanitschke, unpublished results). With a daily intake of 2-4 g of ADS those concentrations of $100-400 \mathrm{mg} / \mathrm{dl}$ can be expected in the distal ileum. In a double blind, placebo controlled crossover study ADS indeed increased ileal output in healthy volunteers with ileostomy after colectomy for ulcerative colitis. ${ }^{14}$

In our in vitro study, ADS stimulated active chloride secretion in the isolated ileal mucosa short circuited in the Ussing chamber. The $I_{s c}$ was enhanced at a threshold concentration of $4 \mathrm{mg} / \mathrm{dl}$ of ADS, when given to the mucosal side. This increase of $I_{s c}$ was associated with only a marginal decrease of epithelial resistance at the higher ADS concentrations caused by an increased chloride conductance, a common finding during stimulation of secretion. ${ }^{14}$ This rules out a paracellular pathway in the mediation of the ADS-induced secretion in contrast with laxatives of the triarylmethane derivative type - for example, oxyphenisatin, which has some chemical similarities with ADS as regards to the diphenolic groups. ${ }^{15}$ In contrast with oxyphenisatin, ADS did not alter mucosal morphology, also suggesting a transcellular pathway of the ADS-induced secretion. This cellular secretion is inhibited, when the transcellular permeation of chloride is blocked by furosemide at the basolateral cell membrane, ${ }^{1617}$ showed by the absence of an increase in $I_{s c}$. This increase of $I_{s c}$ only accounted for a part of the ADS-induced chloride secretion, however. The other part is electrically silent either because of a concomitant cation secretion or anion absorption, which is represented by the change in residual current $\left(I_{R}\right)$. Absorption of the negatively charged ADS molecule could be responsible, but the applied ADS concentration is quantitatively too small to account for the calculated changes in $\mathrm{I}_{\mathrm{R}}$. In addition, complete recovery of ADS was found in ileostomy fluid after a single oral dose. ${ }^{18}$

Prostaglandins cannot be considered as mediators of the ADS-induced secretion because pretreatment with indomethacin in a concentration able to abolish the endogenous prostaglandin biosynthesis ${ }^{1319}$ did not inhibit the increase of $I_{s c}$ by ADS. This is consistent with the finding of an unchanged prostaglandin output in patients with ileostomies under treatment with ADS ${ }^{14}$ Cyclic AMP can also be ruled out as mediator of the induced secretion, as ADS had no influence on the cAMP content in the intestinal mucusa (unpublished results).

Because ADS was effective only by mucosal application, this substance must have a direct influence on the ion transfer mechanisms of the luminal cell membrane leading preferentially to a reversible induction of an active chloride secretion. This secretagogue action is related to a special structure of the ADS-double molecule, because that of SASP has no effect on intestinal ion transfer, but that of HB313, where 5-ASA is connected to paraaminosalicylic acid, decreases net water and ion absorption. ${ }^{20}$ Therefore, other substitutes of SASP have also to be studied on their effect on water and ion transfer.

Although the intact double molecule of ADS causes secretion in the ileum and colon in concentrations within the therapeutic range,$^{12}$ healthy subjects do not develop diarrhoea ${ }^{910}$ because during the 
delayed transit in the colon ADS is split by complete azoreduction into the non-secretagogue 5-ASA, ${ }^{21}$ and the increased fluid volume from the ileum is compensated by the high absorptive capacity of the healthy colon mucosa..$^{223}$ When diarrhoea develops in patients with ulcerative colitis under treatment with ADS, the absorptive capacity of the colon may have been too greatly restricted in these patients to handle the increased fluid volume appropriately ${ }^{24}$ and/or intestinal transit time may be too short for sufficient cleavage of the secretagogue ADS as has been similarly suggested for sulphasalazine. ${ }^{25}$

Part of these results were presented at the sixth Meeting of the European Intestinal Transport Group, Pamplona, Spain, 1984.

\section{References}

1 Schröder H, Campbell DES. Absorption, metabolism and excretion of salicylazosulfapyridine in man. Clin Pharmacol Ther 1972; 13: 539-51.

2 Peppercorn MA, Goldman P. Distribution studies of salicylazosulfapyridine and its metabolites. Gastroenterology 1973; 64: 240-5.

3 Azad Khan AH, Piris J. Truelove SC. An experiment to determine the active therapeutic moiety of sulphasalazine. Lancet 1977; ii: 892-5.

4 van Hees PAM, Bakker JH, van Tongeren JHM. Effect of sulphapyridine, 5-aminosalicyclic acid, and placebo in patients with idiopathic procitis: a study to determine the active therapeutic moiety of sulphasalazine. Gut 1980; 21: 632-5.

5 Klotz U, Maier K, Fischer C, Heinkel H. Therapeutic efficacy of sulfasalazine and its metabolites in patients with ulcerative colitis and Crohn's disease. NEngl J Med 1980; 303: 1499-502.

6 Das KM, Eastwood MA, McManus JPA, Sircus W. Adverse reactions during salicylazosulfapyridine therapy and the relation with drug metabolism and acetylator phenotype. $N$ Engl J Med 1973; 289: 491-5.

7 Taffet SL, Das KM. Desensitation of patients with inflammatory bowel disease to suldasalazie. Am J Med 1983; 73: 520-4.

8 Goldman P. Will there be a next generation of sulfasalazine? Gastroenterology 1982; 83: 1138-41.

9 Willoughby CP, Aronsson JK, Agback H, Bodin NO, Truelove SC. Distribution and metabolism in healthy volunteers of disodium azodisalicylate, a potential therapeutic agent for ulcerative colitis. Gut 1982; 23: 1081-7.

10 van Hogezand R, van Hees PAM, Zwangenburg B, van Rossum JM, van Tongeren JHM. Disposition of sodium azodisalicylate in healthy subjects. A possible new drug for inflammatory bowel disease. Gastroenterology 1985; 88: $717-22$.
11 Sandberg-Gertzén H, Järnerot G. Azodisal sodium in the treatment of ulcerative colitis. A study of tolerance and relapse prevention properties. Gastroenterology 1986; 90: 1024-30.

12 Goerg KJ, Wanitschke R, Breiling K, Franke M, Meyer zum Büschenfelde KH. The effect of disodium-azobis (DSA) on water and electrolyte transfer of the rat ileum and colon in vivo compared with sulfasalazine (SASP) 5-aminosalicylic acid (SA) and sulfapyridine (SP). [Abstract]. Gastroenterology 1984; 86: 1091.

13 Bukhave K, Rask-Madsen J. Saturation kinetics applied to in vitro effects of low prostaglandin $E_{2}$ and $F_{2 k}$ concentrations on ion transport across human jejunal mucosa. Gastroenterology 1980; 78: 32-42.

14 Sandberg-Gertzén H, Järnerot G, Bukhave K, Lauritsen K, Rask-Madsen J. Effect of azodisal sodium and sulphasalazine on ileostomy output of fluid and $\mathrm{PGE}_{2}$ and $\mathrm{PGF}_{2 \alpha}$ in subjects with a permanent ileostomy. Gut 1986; 27: 1306-11.

15 Nell G, Rummel W. Action mechanisms of secretagogue drugs. In: Handbook of experimental pharmacology. Vol 70/II. Berlin: Springer Verlag, 1984: 461-508.

16 Field M. Secretion of electrolytes and water by mammalian small intestine. In: Johnson LR, ed. Physiology of the gastrointestinal tract. New York: Raven Press, 1981: 963-82.

17 Heintze K, Stewart CP, Frizell RA. Sodium-dependant chloride secretion across rabbit descending colon. Am J Physiol 1983; 244: G357-65.

18 Sandberg-Gertzén H, Ryde M, Järnerot G. Absorption and excretion of a single $1-\mathrm{g}$ dose of azodisal sodium in subjects with ileostomy. Scand J Gastroenterol 1983; 18: $107-11$.

19 Goerg KJ, Roux M, Wanitschke R, Meyer zum Büschenfelde KH. Die Bedeutung des Meißnerschen Plexus für die sekretorische Funktion der Colonschleimhaut. Z Gastroenterol 1986; 24: suppl 3: 70-8.

20 Goerg KJ, Wanitschke R, Diehl R, Leonhard E, Meyer zum Büschenfelde KH. Effect of azodisalicylate and $\mathrm{HB}$ 313 on water and ion transfer in the rat ileum in vivo and in vitro. [Abstract]. Gastroenterology 1985; 88: 1397.

21 Lauritsen K, Hansen J, Ryde M, Rask-Madsen J. Colonic azodisalicylate metabolism determined by in vivo dialysis in healthy volunteers in patients with ulcerative colitis. Gastroenterology 1984; 86: 1496-500.

22 Debongie JC, Phillips SF. Capacity of the human colon to absorb fluid. Gastroenterology 1968; 74: 698-703.

23 Rask-Madsen J. Absorptive function of the colon. In: Barbara L, Miglioli M, Phillips SF, eds. New trends in pathophysiology and therapy of the large bowel. Amsterdam: Elsvier/North-Holland Biomedial Press, 1983: 19-34.

24 Rask-Madsen J. Functional alterations in ulcerative colitis. In: Robinson JWL, ed. Intestinal ion transport. Lancaster: MTP Press, 1976: 381-97.

25 van Hees PAM, Tuinte JHM, van Rossum JM, van Tongeren JHM. Influence of intestinal transit time on azo-reduction of salicylazosulphapyridine (Salazopyrin). Gut 1979; 20: 300-4. 